\title{
Effects of Prolonged Administration of Aqueous Extract of Ocimum gratissimum (Scent Leaf) on Blood Glucose and Lipid Profile in Alloxan Induced Diabetic Albino Rats
}

\author{
Ufele Angela Nwogor \\ Zoology Department, Nnamdi Azikiwe University, Awka, Anambra State, Nigeria
}

Email address:

ufeleangel@yahoo.com

\section{To cite this article:}

Ufele Angela Nwogor. Effects of Prolonged Administration of Aqueous Extract of Ocimum gratissimum (Scent Leaf) on Blood Glucose and Lipid Profile in Alloxan Induced Diabetic Albino Rats. American Journal of Biomedical and Life Sciences. Vol. 4, No. 3, 2016 , pp. $30-34$. doi: $10.11648 /$ j.ajbls.20160403.12

Received: March 31, 2016; Accepted: April 15, 2016; Published: April 28, 2016

\begin{abstract}
This study was aimed at comparing the antidiabetic and antihyperlipidemic activities of various doses (1.0, 2.0ml and $3.0 \mathrm{ml}$ ) of aqueous extract of Ocimum gratissimum and glibenclamide (a reference hypoglycemic drug). Ninety (90) male wistar albino rats were used. The rats were divided into six groups (A, B, C, D, E and F) of five rats each. The experiment was replicated three times. The first group, A was non diabetic while B to $\mathrm{F}$ was made diabetic using alloxan. Results obtained showed that there was a significant difference $(\mathrm{p}<0.05)$ in blood glucose level $(\mathrm{mg} / \mathrm{dl})$ following the administration of Ocimum gratissimum leaf extract in groups D and E $(139.96 \pm 7.2 \mathrm{mg} / \mathrm{dl}$ and $106.64 \pm 4.30 \mathrm{mg} / \mathrm{dl})$ when compared to the diabetic control group B $(299.34 \pm 1.30 \mathrm{mg} / \mathrm{dl})$. Administration of glibenclamide (antidiabetic drug) also resulted in a significant drop in the blood glucose levels between week 1 and 4 . The effects of Ocimum gratissimum and glibenclamide on the blood glucose level are significantly the same at the final week (week 4). The effect of $2.0 \mathrm{ml}$ and $3.0 \mathrm{ml}$ (groups C and D) of aqueous extract of Ocimum gratissimum on total cholesterol, triglycerides and low density lipoprotein cholesterol (LDL-C) compared favourably with the reference drug (glibenclamide) whereby they all have significant difference $(\mathrm{P}<0.05)$ on these biochemical parameters when compared to the diabetic control. All doses of Ocimum gratissimum aqueous leaf extract increased the level of high density lipoprotein cholesterol $(37.41 \pm 1.07 \mathrm{mg} / \mathrm{dl}, 42.09 \pm 1.22 \mathrm{mg} / \mathrm{dl}$ and $49.76 \pm 0.63 \mathrm{mg} / \mathrm{dl})$ when compared to the diabetic control group (32.27 \pm 1.68$)$. The effect of highest dose $(3.0 \mathrm{ml})$ of Ocimum gratissimum extract on high density lipoprotein cholesterol (HDL-C) (49.76 \pm 0.63 ) compares favourably with the effect seen on the reference drug (glibenclamide) (50.15 \pm 1.17$)$. The results suggest that the leaf aqueous extract of Ocimum gratissimum at $3.0 \mathrm{ml}$ dosage has antidiabetic and antihyperlipidemic effect and would be of benefit in the treatment and management of diabetes mellitus, controlling the blood sugar level as well as in preventing or delaying the onset of diabetes mellitus.
\end{abstract}

Keywords: Albino Rats, Ocimum gratissimum, Blood Glucose and Lipoprotein Cholesterol

\section{Introduction}

Diabetes mellitus is a metabolic disorder in which a person has a high blood sugar level, either because the body does not produce enough insulin, or because body cells do not properly respond to the insulin that is being produced [7]. Diabetes mellitus occurs when insulin is not secreted by the pancreas in sufficient amounts or because cells do not respond to the insulin that is produced [4]. Insulin is a peptide hormone, produced by beta cells of the pancreas, and is central to regulating carbohydrate and fat metabolism in the body [3]. Diabetes mellitus is a serious chronic condition which has several complications including diabetic nephropathy, diabetic neuropathy, coronary heart disease and hypertension. These complications may be delayed, lessened or prevented by maintaining blood glucose level close to normal.

Symptoms of diabetes mellitus include polyuria (production of large volume of urine), polydipsia (abnormally intense thirst) polyphagia (increased appetite) general fatigue and weight loss [7]. Long standing diabetes has been documented to cause structural and functional cardiac impairment, which 
was found to lead to ischemic heart diseases, cardiomyopathy and congestive heart failure [6].

Dyslipidemia (a condition when lipid levels in the bloodstream are too high or low) is common in diabetes, as both insulin deficiency and insulin resistance affects enzymes and pathways of lipid metabolism [6].

Type 1 diabetes results from the body's failure to produce insulin. It is partly inherited and triggered by certain infections. Type I diabetes mellitus is also called insulin dependent diabetes mellitus (IDDM). Type 2 diabetes mellitus which is also called Non-insulin dependent diabetes mellitus (NIDDM) or adult-onset diabetes is a metabolic disorder that is characterized by high blood glucose in the context of insulin resistance and relative insulin deficiency. World Health Organization [24] identified diabetes as an epidemic underway since about 164 million people worldwide were affected in 2000 and a possible increase to 366 million by 2030 has been projected [25]. In Nigeria, the prevalence of diabetes mellitus according to a national survey reveals that 2.2 percent, that is $2-3$ in every 100 persons are suffering from the disease [13]. The populations of people with this disease are found mostly in urban areas due to their sedentary life style.

Insulin therapy affords glycaemic control in type I diabetes, yet its shortcomings such as ineffectiveness on oral administration, short shelf life, the requirement of constant refrigeration, fatal hypoglycemia in excess dosage, resistance due to prolonged administration, limits its usage. Again, oral hypoglycaemic agents currently used in clinical practice have characteristic profiles of serious side effects such as weight gain, gastrointestinal discomfort and nausea, liver failure and diarrhoea [22]. Hence, search for a drug with low cost, more potency and without adverse side effects is being pursued in several laboratories around the world.

In the recent years, there has been renewed interest in plant medicine [10]. Herbal medicines however appear to be a potent alternative with fewer side effects from various studies reviewed. Today, a large number of drugs in use are derived from plants. Ocimum gratissimum is among the traditionally used herbal plants to treat different ailments. It is a plant belonging to Lamiceae family. In eastern Nigeria, it serves as a source of stimulation and condiment in soup due to its minty aromatic flavor [21]. Traditionally, Ocimum gratissimum has been used for the treatment of headache, diarrhea, kidney infections, cough, convulsions, gastric ulcer, conjunctivitis and wart worms $[2 ; 17 ; 20]$. The major constituents of Ocimum gratissimum include: aromatic and volatile oil, linolenic acid, oleic acid, alkaloid, flavonoid and saponin [1].

Considering the phytochemical constituents of Ocimum gratissimum and its array of uses in traditional medicine therefore necessitated the investigation into this study of effects of aqueous extract of Ocimum gratissimum leaves (scent leaf) on blood glucose and lipid profile in alloxan induced diabetic wistar albino rats. Alloxan is a toxic glucose analogue, which selectively destroys insulin-producing cells in the pancrease (beta cells) when administered to rodents and many other animal species [11]. Glibenclamide, also known as glyburide is an antidiabetic drug. Glibenclamide has been shown to bind more efficiently to the ischemic hemisphere [16]. Albino rats (Rattus norvegicus) were used in this experiment because rats were used for several scientific experiments and eventually the laboratory rat became the first animal domesticated for purely scientific reasons [9]. Most of the research done with rat can also work with other mammals including man that is the reason for using rats.

\section{Materials and Methods}

\subsection{Procurement of Experimental Animal}

Ninety (90) healthy adult male wistar albino rats having average weight of about $180 \mathrm{~g}$ were used for the experiment. The wistar albino rats were maintained and housed in six (6) cages with five (5) rats in each. They were all fed with guinea chick mash. The animals were maintained under standard laboratory condition, that is, a well aerated room with alternating, light and dark cycle of 12 hours each. They were allowed to acclimatize with the environment for one week before the commencement of the experiment.

\subsection{Experimental Treatments}

The animals that were used for the experiment were randomly placed into six (6) groups (A, B, C, D, E and F) of five rats each. The administration of aqueous extract of Ocimum gratissimum and glibenclamide (a standard hypoglycemic drug) was done orally.

Group A contained rats that were non diabetic. In this group, $2.0 \mathrm{ml}$ of distilled water was orally administered using gastrointestinal cannular. This served as normal control group.

Group B contained untreated Diabetic rats. In this group, $2.0 \mathrm{ml}$ of distilled water was administered daily. This served as the diabetic control.

Group C contained Diabetic rats, this group received oral dose of $1.0 \mathrm{ml}$ Ocimum gratissimum extract daily.

Group D contained diabetic rats, they received oral dose of $2.0 \mathrm{ml}$ Ocimum gratissimum extract daily.

Group E contained diabetic rats, they received oral dose of $3.0 \mathrm{ml}$ Ocimum gratissimum extract daily.

Group $\mathrm{F}$ contained diabetic rats. This group received glibenclamide (a standard hypoglycemic drug) at a dose of $1.0 \mathrm{ml}$ daily.

Treatment lasted for four weeks. Blood glucose was measured weekly (days 1, 7, 14 and 28) after an overnight fast.

The blood glucose level of the rats was checked before the administration of alloxan using one touch glucometer. This gives a digital result within 45 seconds. The rats that subjected to diabetes were fasted for 16 hours but with free access to water after which they received an intraperitoneal injection of $1.0 \mathrm{ml}$ of alloxan (Sigma LTD, USA). The animals were allowed to have free access to food and water after alloxan injection.

After 48 hours of alloxan injection, blood was collected and 
their glucose level was checked using one touch glucometer and test strips. Their blood glucose level was observed to be far much higher than normal (above $200 \mathrm{mg} / \mathrm{dl}$ ).

On day 28, the experimental animals were fasted for 12 hours and blood was collected and plasma triglycerides and total cholesterol (TG and TC) levels were measured using enzymatic colorimetic diagnostic kits (from Randox Laboratories, UK) in which the GPO-PAD method of Richmond [18] as applied in Randox kit was used for the determination of LDL and HDL-cholesterol.

\subsection{Data Analysis}

The blood sugar level, plasma triglycerides and total cholesterol (TG and TC) levels were expressed as mean \pm standard error of mean, analyzed using one-way analysis of variance (ANOVA). The comparison of mean was separated using a post Hoc test (Least Significant Difference), [26].

\section{Results}

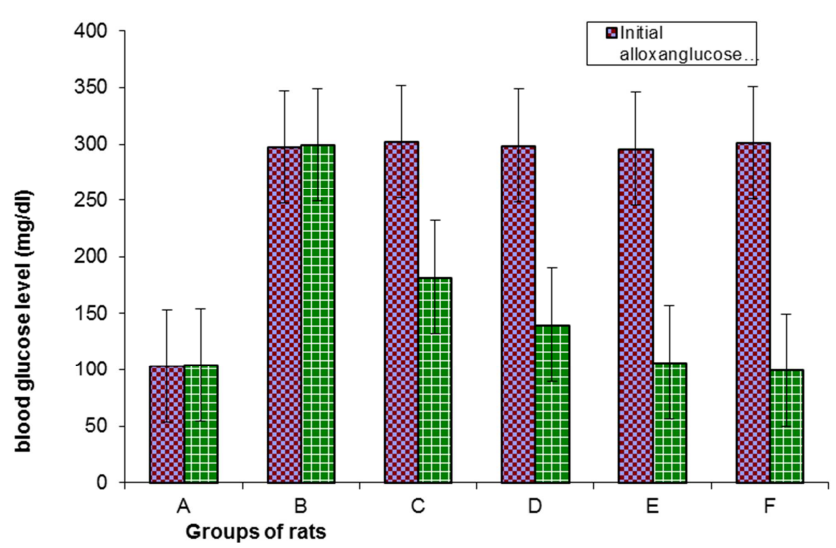

Figure 1. Mean blood glucose level of rats subjected to different treatments.

The mean fasting blood glucose levels $(\mathrm{mg} / \mathrm{dl})$ of diabetic and non diabetic albino rats subjected to different treatments (Ocimum gratissimum leaf extract, glibenclamide and distilled water) for four weeks are presented in Figure 1, the purple bars represents the initial glucose level after administering alloxan, and the green bars represents the final glucose level at the end of the experiment. The mean blood glucose levels of the experimental rats were monitored weekly for a period of 28 days (4 weeks). The fasting blood glucose level of the normal control group A remained within the normal range $(104.14 \mathrm{mg} / \mathrm{dl})$ throughout the experimental period. The diabetic control group $\mathrm{B}$ also maintained their high fasting blood glucose level $(297.29 \mathrm{mg} / \mathrm{dl})$ throughout the experimental period with slight fluctuations. There was a significant difference $(p<0.05)$ in blood glucose level following the administration of Ocimum gratissimum leaf extract in groups C, D and E $(181.95 \mathrm{mg} / \mathrm{dl}, 139.96 \mathrm{mg} / \mathrm{dl}$ and $106.64 \mathrm{mg} / \mathrm{dl}$ ) when compared to the diabetic control group (B) $(299.34 \mathrm{mg} / \mathrm{dl})$. Increasing the concentration of the plant aqueous extract produced a dose and time dependent decrease in blood glucose level over the 28-day (4 weeks) period of administration of the plant extract (Ocimum gratissimum). The values obtained for blood glucose level in Ocimum gratissimum extract treated groups of diabetic rats $(\mathrm{C}, \mathrm{D}$ and $\mathrm{E})$ were lower $(\mathrm{P}<0.05)$ when compared with diabetic control group (B). Administration of glibenclamide (anti diabetic drug) also resulted in a significant drop $(\mathrm{p}<0.05)$ in the blood glucose levels $(99.84 \mathrm{mg} / \mathrm{dl})$. The effects of Ocimum gratissimum and glibenclamide on the blood glucose level are significantly the same at the end of the experiment.

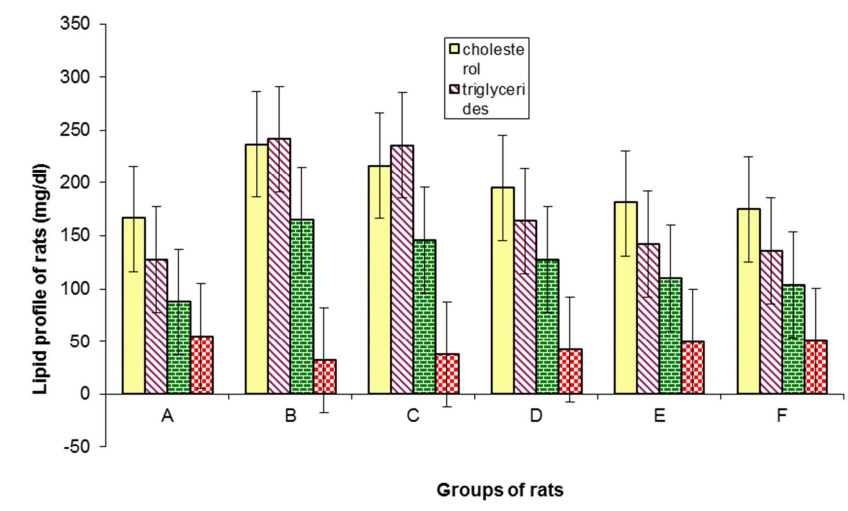

Figure 2. Mean lipid profile of rats subjected to different treatments.

The lipid profile $(\mathrm{mg} / \mathrm{dl})$ of diabetic and non-diabetic albino rats subjected to different treatments (Ocimum gratissimum, glibenclamide and distilled) for 4 weeks is presented in Figure 2 above. Yellow bar represents cholesterol level, purple bars the triglycerides, green bars the LDL(low density lipoprotein) and red bars represents HDL(high density lipoprotein). From the figure 2 above group A had mean cholesterol of $166.38 \mathrm{mg} / \mathrm{dl}$, group B had $236.35 \mathrm{mg} / \mathrm{dl}$, group $\mathrm{C}$ had $216.28 \mathrm{mg} / \mathrm{dl}$, group $\mathrm{D}$ had $195.46 \mathrm{mg} / \mathrm{dl}$, group $\mathrm{E}$ had $180.98 \mathrm{mg} / \mathrm{dl}$ and group $\mathrm{F}$ had $175.07 \mathrm{mg} / \mathrm{dl}$. In triglyceride result group A had $127.42 \mathrm{mg} / \mathrm{dl}$, group B had $241.41 \mathrm{mg} / \mathrm{dl}$, group C had $235.56 \mathrm{mg} / \mathrm{dl}$, group $\mathrm{D}$ had $164.35 \mathrm{mg} / \mathrm{dl}$, group $\mathrm{E}$ had $142.05 \mathrm{mg} / \mathrm{dl}$ and group $\mathrm{F}$ had $135.65 \mathrm{mg} / \mathrm{dl}$. In low density lipoprotein (LDL), group A had $87.55 \mathrm{mg} / \mathrm{dl}$, group $B$ had $165.23 \mathrm{mg} / \mathrm{dl}$, group $\mathrm{C}$ had $145.79 \mathrm{mg} / \mathrm{dl}$, group D had $127.28 \mathrm{mg} / \mathrm{dl}$, group $\mathrm{E}$ had $110.15 \mathrm{mg} / \mathrm{dl}$ and group $\mathrm{F}$ had $103.50 \mathrm{mg} / \mathrm{dl}$. In high density lipoprotein (HDL), group A had $55.04 \mathrm{mg} / \mathrm{dl}$, group B had $32.27 \mathrm{mg} / \mathrm{dl}$, group $\mathrm{C}$ had $37.41 \mathrm{mg} / \mathrm{dl}$, group $\mathrm{D}$ had $42.09 \mathrm{mg} / \mathrm{dl}$, group $\mathrm{E}$ had $49.76 \mathrm{mg} / \mathrm{dl}$ and group $\mathrm{F}$ had $50.15 \mathrm{mg} / \mathrm{dl}$. The effect of high doses $2.0 \mathrm{ml}$ and $3.0 \mathrm{ml}$ (groups $\mathrm{D}$ and $\mathrm{E}$ ) of Ocimum gratissimum on total cholesterol, triglycerides and low density lipoprotein (LDL) compares favourably with the reference drug (glibenclamide)(group F), whereby they all had significant difference $(\mathrm{P}<0.05)$ on these biochemical parameters when compared to the diabetic control(group B). All doses of aqueous extract of Ocimum gratissimum leaf showed significant difference $(\mathrm{P}<0.05)$ in the level of high density lipoprotein cholesterol (HDL-C) when compared to the diabetic control group B. The effect of Ocimum gratissimum on high density lipoprotein cholesterol (HDL-C) compares favourably with that seen in the reference drug (glibenclamide) group $\mathrm{F}$. 


\section{Discussion}

The hypoglycemic action of the Ocimum gratissimum extract seen in this experiment may be attributed to one or a combination of the following: the active principle(s) may have enhanced the activity of residual insulin in the alloxanised animals or promoted glucose uptake by peripheral tissues, by other means; it is also possible that the extract slowed down glucose absorption in the gastrointestinal tract (GIT) or regulated the metabolism of glucose by the liver $[23 ; 8]$.

The increase in the total cholesterol, triglyceride (TG) and Low density lipoprotein cholesterol (LDL-C) levels of diabetic rats observed in this study are in accordance with earlier report documenting increased plasma TG, LDL and cholesterol level in diabetic subject [15]. Diabetes-induced hyperlipidemia has been reported to be attributable to excess mobilization of fat from the adipose due to underutilization of glucose [14]. The significant reduction in trigliceryde, LDL and cholesterol levels of the diabetic rats when treated with aqueous leaves extract of $O$. gratissimum in this study is in support of the findings that most hypoglycaemic plants have potentials of ameliorating diabetic lipid metabolism anomalies. This cholesterol lowering effect was earlier reported by some researchers when used as supplementary diet in normal rats for six months. The hypolipidemic effect of O. gratissimum could be related to its chemical composition, which shows the presence of alkaloids, flavonoids, saponin and cardiac glycosides. All these components are known to reduce serum lipid level in animals [5]. Saponins may lower cholesterol by binding with cholesterol in the intestinal lumen, preventing its absorption, and/or by binding with bile acids, causing a reduction in the enterohepatic circulation of bile acids and increase in its faecal excretion [19]. The increased bile acid excretion is offset by enhanced bile acid synthesis from cholesterol in the liver and consequent lowering of the plasma cholesterol.

Though the precise mechanism by which the leaf extract of Ocimum gratissimum exerts its hypolipidemic effect is not clearly known nor studied, it could not be excluded that the control of glycaemia is a contributing mediator since control of glycaemia is a major determinant of total cholesterol and triglyceride levels [12]. Accordingly, the evolution of glycaemia was parallel to lipid parameters in both the normal control and the diabetic control rats of this study.

\section{Conclusion}

In conclusion, the aqueous leaf extract of Ocimum gratissimum administered orally for a period of four (4) weeks produced decreased blood glucose level and reduced the lipid imbalances associated with diabetes mellitus in albino rats. The plant has a hypoglycemic effect and may be safe when taken orally. If the results obtained with rats can also apply to man, Ocimum gratissimum will be highly recommended for diabetic patients.

\section{References}

[1] Abdel-barry, I. A., Hassan, J. A., Mohammed, T. S. (2000). The hypoglycemic and anti-hyperglycemic effects of Citrullus colocynthis fruit aqueous extract in normal and alloxan induced diabetic rats. Journal of Ethnopharmacology, 71:325330 .

[2] Celso, V., Nakamar, I. E., Tania, U. J. (2005). Anti bacteria activity of Ocimum gratissimum essential oil. Momarias do mitituto oswaldo cruz, 94(5): 675-678.

[3] Chang, X., Jorgensen, A. M., Bardium, P., Led, J. J. (1997). Solution structures of the R6 human insulin hexamer. Biochemistry. 36(31): 9409-22.

[4] David G. G, (2011) Greenspan's basic and clinical endocrinology $\left(9^{\text {th }}\right.$ edition) New York pp 45-48.

[5] Ezekwe, C. I, Obidoa, O (2001). Biochemical effect of Vernonia amygdalina on rats liver microsome. Nigeria Journal of Biochemical Molecular Biology, 16: 1745-1798.

[6] Gibbons, G. F. (1998). Hyperlipidemia of diabetes. Clinical Science.71: 477-486.

[7] Gineberg, H. N. (2000). Insulin resistance and cardiovascular disease. Journal of Clinical Investigation, 106: 453-459.

[8] Gupta, S. S (1994). Prospects and perspectives of natural plant products in medicine; Indian Journal of Pharmacology. 26:112.

[9] Krinke, G. J. (2000) History, strains and models. The Laboratory Rat (Handbook of exp. Animals). Academic Press. Pp 3-16.

[10] Ladeji, O., Omekarah, I., Solomon, M. S. (2003) Hypoglycemic properties of aqueous bark extract of Oeiba pentandra in streptozotocin-induced diabetic rats. Journal of Ethnopharmacology, 84: 139-142.

[11] Lenzen, S. (2008). The mechenisms of alloxan and streptozotocin induced diabetes. Diabetologia, 51(2): 216-226.

[12] Markku, L. (1995). Epidemiology of diabetes dyslipidemia. Diabetes Review, 3: 408-422.

[13] National Diabetes Association (2000). Nutrition recommendations and principles for people with diabetes mellitus. Diabetes Care; Pp 543-546.

[14] Nimenibo-Uadia, R. (2003). Effect of aqueous extract of Canavalia ensiformis seeds on hyperlipidaemia and hyperketonaemia in alloxan-induced diabetic rats. African Journal of Biochemistry, 15: 7-15.

[15] Oberley, L. W (1988). Free radicals and diabetes. Biology and Medicine journal, 5: 113-124.

[16] Ortega, F. J., Gimeno-Bayon, J., Espinosa-Parrilla, J. F., Carrasco, J. L., Batlle, M., Fugliese, M., Mahu, N., Rodriguez, M.J. (2012). ATP-dependent potassium channel blockade strengthens microglial neuroprotection after hypoxia-ischemia in rats. Experimental Neurology, 235(1): 282-296.

[17] Pessoa, L. M., Morais, S. M., Bevilaqua, C. L., Luciano, J. H. (2002). Anthelmintic activity of essential oil of Ocimum gratissimum and eugenol against Haemonchus contortus. Veterinary Parasitology, 109: 59-63. 
[18] Richmond, W. O. (1973). Cholesterol enzymatic colorimetric test, Chop-PAP method of estimation of total cholesterol in serum. Clinical Chemistry, 191: 1350-1356.

[19] Rotimi, S. O., Omotosho, O. E., Rotimi, O. A. (2011). Persistence of acidosis in alloxan-induced diabetic rats treated with the juice of Asystasia gangetica leaves. Pharmacognosy Magazine, 8(7): 25-30.

[20] Socorro, V. F., Madaira, U. C., David, N. (2002). Relaxant effect of the essential oil of Ocimum gratissimum on isolated ileum of the guinea pig. Journal of Ethnopharmacology, 81(1): 3-5.

[21] Sofowora, A. (1993). Medicinal Plants and Traditional Medicine In Africa. Spectrum Book LTD, Ibadan, Nigeria. $P p$ 345-349.

[22] Suba, V. H., Murugesan, T., Manda, S. C., Sahu, B. P. (2004).
Antidiabetic potential of Barleria lupilina extract in rats. Phytomedicine, 11:202-205.

[23] Twaij, H. A., Al-Badr, A. (1988). Hypoglycaemic activity of Artemisia herba-alba. Journal of Ethnopharmacology, 24: 123-126.

[24] WHO Expert Committee (2001). The selection and use of essential medicines. World Health Organization Technical Report Series, 65: 1-249.

[25] Wild, S., Roglic, G. A., Green, A., King, H., (2004). Prevalence of diabetes: Estimates for 2000 and projection for 2040. Diabetes care; 27(5): 1047-1053.

[26] William, A. C., and George, W. S. (2008). Statistical Methods, $6^{\text {th }}$ Ed., The Iowa State University Press. Ames, Iowa, USA. Pp. 167-263. 